\title{
RNA Sequence
}

National Cancer Institute

\section{Source}

National Cancer Institute. RNA Sequence. NCI Thesaurus. Code C89252.

The sequence of nucleotide residues along an RNA chain. 